\title{
On-pump beating heart versus conventional coronary artery bypass grafting: comparative study on early and long-term clinical outcomes
}

\author{
Ho Jin Kim, You Na Oh, Min Ho Ju, Joon Bum Kim, Sung-Ho Jung, Cheol Hyun Chung, Jae Won Lee, \\ Suk Jung Choo
}

Department of Thoracic and Cardiovascular Surgery, Asan Medical Center, University of Ulsan College of Medicine, Seoul, Republic of Korea Contributions: (I) Conception and design: HJ Kim, JB Kim, SJ Choo; (II) Administrative support: YN Oh, MH Ju; (III) Provision of study materials or patients: JB Kim, SH Jung, SJ Choo, CH Chung, JW Lee; (IV) Collection and assembly of data: HJ Kim, YN Oh, MH Ju; (V) Data analysis and interpretation: HJ Kim, JB Kim, SJ Choo; (VI) Manuscript writing: All authors; (VII) Final approval of manuscript: All authors.

Correspondence to: Suk Jung Choo, MD, PhD. Department of Thoracic and Cardiovascular Surgery, Asan Medical Center, University of Ulsan College of Medicine, 88, Olympic-ro 43-gil, Songpa-gu, Seoul 05505, Republic of Korea. Email: SJChoo@amc.seoul.kr.

\begin{abstract}
Background: We reviewed our experience with on-pump beating (OPB) heart coronary artery bypass grafting $(\mathrm{CABG})$ to evaluate the impacts of obviating aortic cross-clamping and cardioplegic arrest on clinical outcomes compared with conventional CABG (C-CABG).

Methods: Between 2006 and 2012, elective isolated cardiopulmonary bypass (CPB)-assisted CABG was consecutively performed in 645 patients (mean patient age $63.3 \pm 9.1$ years, 471 women) with 254 (39.4\%) undergoing OPB-CABG and 391 (60.6\%) undergoing C-CABG. The early and long-term clinical outcomes were compared between the two groups after adjusting for risk profiles through propensity score (PS) analyses.

Results: The OPB-CABG group presented significant morbidities more frequently than the C-CABG group, including severe chronic kidney disease $(\mathrm{CKD})(\mathrm{P}=0.026)$, severe chest pain $(\mathrm{P}<0.001)$, and poor left ventricular function $(\mathrm{P}<0.001)$. Early mortality occurred in $6(2.4 \%)$ and $2(0.5 \%)$ patients in the OPB- and C-CABG group, respectively $(\mathrm{P}=0.087)$. The number of distal anastomosis was comparable between the two

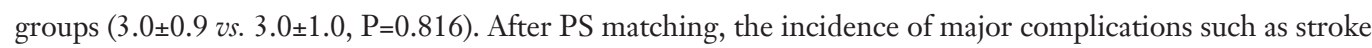
$(\mathrm{P}>0.99)$ and new-onset dialysis $(\mathrm{P}=0.109)$ was comparable. During a median follow-up of 81.0 months (quartiles 1-3, 66.6-95.0 months), 118 patients died and the PS-matched models showed no significant between-group differences in the risk of overall death [hazard ratio (HR), 1.19; 95\% confidence interval (CI), 0.72-1.95; P=0.507] and major adverse cardiac events (MACE) (HR, 1.49; 95\% CI, 0.67-3.31; P=0.328).

Conclusions: The OPB strategy may be as safe and effective as the conventional strategy during CABG among patients with similar risk profiles. A prospective randomized trial is warranted to better ascertain the beneficial impact of OPB-CABG as both a viable and a durable alternative strategy to C-CABG.
\end{abstract}

Keywords: Coronary artery bypass grafting (CABG); cardiopulmonary bypass (CPB); mortality

Submitted Oct 10, 2017. Accepted for publication Mar 23, 2018.

doi: $10.21037 /$ jtd.2018.05.14

View this article at: http://dx.doi.org/10.21037/jtd.2018.05.14

\section{Introduction}

The optimal coronary revascularization strategy remains debated $(1,2)$. Although conventional coronary artery bypass grafting $(\mathrm{C}-\mathrm{CABG})$ remains the gold standard, the use of cardiopulmonary bypass (CPB), aortic cross-clamping, and cardioplegic arrest may arguably increase the risk of serious neurologic and renal complications, as well as ischemic myocardial injury $(3,4)$. Off-pump CABG (OPCAB) has 
been viewed as a potentially ideal strategy of avoiding some of the more prominent complication risks of C-CABG, by obviating the use of CPB and cardioplegic arrest altogether while achieving the surgical objectives in a qualitatively similar manner. However, recent studies have increasingly reported inferior long-term survival outcomes with $\mathrm{OPCAB}$, presumably owing to the limitations associated with the inherently more challenging nature of the surgical technique $(1,5,6)$.

On-pump beating (OPB) heart CABG (OPB-CABG) may have the potential to reap the benefits of both $\mathrm{OPCAB}$ and $\mathrm{C}-\mathrm{CABG}$ while avoiding their major drawbacks $(7,8)$. Unlike OPCAB, OPB-CABG provides a more stable mechanical platform for performing distal anastomosis while maintaining the beating heart status albeit on a brief period of CPB support. This dependence on CPB, however, may be argued as being a limitation that may nullify any purported advantages claimed by OPB-CABG over either OPCAB or C-CABG. Nevertheless, in certain high-risk conditions such as myocardial infarction or left ventricular dysfunction, OPB-CABG has reportedly shown greater benefits compared with C-CABG in terms of reducing the early morbidity and mortality rates (9-11). In light of these issues, we reviewed our clinical experiences with OPB-CABG and analyzed its efficacy as a viable alternative strategy for coronary revascularization by comparing the early and long-term results with those of C-CABG.

\section{Methods}

\section{Patients}

Among a total of 1,251 patients undergoing CABG with CPB support between January 2006 and December 2012, we identified 645 consecutive patients who underwent elective isolated CABG after excluding patients undergoing concomitant valvular or aortic surgery $(n=544)$ and emergent/urgent surgeries $(n=62)$. Of these patients, 254 (39.4\%) underwent OPB-CABG (OPB-CABG group), whereas 391 (60.6\%) underwent C-CABG with cardioplegic arrest and aortic cross-clamping (C-CABG group).

The decision to perform C-CABG or OPB-CABG was influenced by several factors such as the patient's demographic and clinical profiles, including left ventricular ejection fraction, site of coronary lesions, or the presence of neurological or renal dysfunction. The decision was ultimately left to the discretion of the operating surgeon who considered all of these factors holistically. The study was approved by the institutional ethics committee/review board of Asan Medical Center (No. 2016-0225), which waived the requirement for informed consent owing to the retrospective study design.

\section{Surgical procedure}

All CABG procedures were performed through a median sternotomy by sufficiently experienced attending surgeons. In situ internal thoracic arteries (ITAs) were harvested in either a skeletonized or pedicled fashion per the operating surgeon's preference. All saphenous vein grafts (SVGs) and radial arteries were harvested by open technique. CPB was instituted by cannulating the distal ascending aorta and right atrium after systemic heparinization (300 IU/kg) with a target activated clotting time of $\geq 480$ s. In the C-CABG group, the aorta was cross-clamped and myocardial protection was achieved with intermittent, antegrade tepid blood cardioplegic infusion $\left(22-32{ }^{\circ} \mathrm{C}\right)$. After the first induction of cardioplegic arrest, subsequent cardioplegia was delivered every $20-30 \mathrm{~min}$. The patient's body temperature was maintained between 28 and $34^{\circ} \mathrm{C}$.

In the OPB-CABG group, bypass grafting was performed on the beating heart under CPB. A vent was passed through the right superior pulmonary vein if the left ventricular was distended during cardiac manipulation. To prevent hypothermia-induced ventricular fibrillation, the body temperature was not actively cooled, but the temperature was allowed to drift between 32 and $34{ }^{\circ} \mathrm{C}$. An Octopus stabilizer (Medtronic, Minneapolis, MN, USA) was routinely used for myocardial immobilization. When the grafts needed to be anastomosed to the ascending aorta, proximal anastomosis was performed on the arrested heart before the release of the aorta cross-clamp in the C-CABG group. During OPB-CABG, the patients underwent proximal anastomosis using either the HEARTSTRING Proximal Seal System (Guidant Corporation, Santa Clara, CA, USA) or aortic side clamping.

The left ITA was preferentially used as the first bypass graft of choice for revascularizing the left anterior descending coronary artery, whenever feasible. The determination of conduit type and configuration for bypassing the other coronary artery territories (right coronary and left circumflex territories) were based on conduit graft availability, sites of target vessels and territories, and surgeon preference (12). 


\section{Outcomes of interest}

The primary early outcomes of interest were the early mortality and early major postoperative morbidities within 30 days of the operation or during hospitalization, including low cardiac output syndrome requiring mechanical circulatory support, early stroke, acute kidney injury requiring new dialysis, mediastinal bleeding, pneumonia, sternal wound infection, and new-onset atrial fibrillation. The primary long-term outcome of interest was allcause death (13). Other long-term outcomes of interest were major adverse cardiac events (MACE) including myocardial infarction, coronary revascularization, stroke, and congestive heart failure requiring hospitalization.

\section{Statistical analysis}

The R software (version 3.4.0; R Foundation for Statistical Computing, Vienna, Austria; http://www.r-project.org/) was used for statistical analysis. Categorical variables, expressed as percentages or frequencies, were compared using the $\chi^{2}$ test. Continuous variables, expressed as either mean \pm standard deviation (SD) or median with range (or quartiles 1-3), were compared using Student's $t$-test. Kaplan-Meier curves were made to delineate the time-related cumulative incidence of all-cause death and MACE. Intergroup comparisons were conducted with log-rank tests.

To emulate a randomized trial in which risk factors affecting the postoperative clinical outcomes are evenly distributed between the two groups, we performed adjustments with propensity scores (PSs) as a matching tool to yield comparable $\mathrm{C}-\mathrm{CABG}$ and OPB-CABG groups (14). The PS, conditional on all relevant baseline variables and comorbidities, was the predicted probability of the patient to receive OPB-CABG in either of the two groups. The PSs were estimated using the logistic regression model and the log-binomial model incorporating the 27 baseline covariates listed in Table 1. The multicollinearity for each covariate was tested by examining the variance of inflation factors (VIFs), with a value of VIF $\geq 10$ considered to indicate excessive multicollinearity. The balance between the two groups after adjustment was assessed with standardized mean differences (SMDs).

PS-matched pairs were generated by matching between the OPB-CABG and C-CABG groups on the logit of the PS with the use of calipers of width $\leq 0.2$ of the SD of the logit of the PS. A conditional logistic regression model and Cox proportional hazards model were used to evaluate the impact of the OPB technique on the early and other long- term outcomes in the PS-matched pairs. The proportional assumption in the Cox model was evaluated with Schoenfeld residuals, which yielded no evidence to suggest rejecting the assumption about the long-term outcomes. All reported $\mathrm{P}$ values were two-sided, and the results were considered statistically significant if $\mathrm{P}<0.05$.

\section{Results}

\section{Baseline characteristics and operative profiles}

The baseline demographics and clinical characteristics of the two groups are summarized in Table 1. In general, the OPB-CABG group showed higher risk profiles compared with the C-CABG group; the OPB-CABG group patients presented with hyperlipidemia $(\mathrm{P}=0.009)$, chronic obstructive pulmonary disease $(\mathrm{P}<0.001)$, severe chronic kidney disease $(\mathrm{CKD})(\mathrm{P}=0.026)$, and severe chest pain (Canadian Cardiovascular Society class 3 or $4, \mathrm{P}<0.001$ ) or dyspnea (New York Heart Association class 3 or $4, \mathrm{P}<0.001$ ) more frequently than those in the $\mathrm{C}-\mathrm{CABG}$ group.

With regards to the echocardiographic profiles, the patients in the OPB-CABG group presented with lower left ventricular ejection fraction $(51.5 \% \pm 13.8 \% v s$. $56.0 \% \pm 11.1 \%, \mathrm{P}<0.001)$, greater left ventricular endsystolic $(36.5 \pm 9.8$ vs. $34.3 \pm 8.0 \mathrm{~mm}, \mathrm{P}=0.003)$ and enddiastolic (52.6 \pm 7.5 vs. $51.5 \pm 6.2 \mathrm{~mm}, \mathrm{P}=0.037)$ dimensions, and higher peak tricuspid regurgitation pressure gradient $(25.2 \pm 8.5$ vs. $22.5 \pm 5.5 \mathrm{~mm}, \mathrm{P}<0.001)$ than those in the C-CABG group.

The number of distal anastomosis $(3.0 \pm 0.9$ vs. $3.0 \pm 1.0$, $\mathrm{P}=0.816)$, $\mathrm{CPB}$ time $(79 \pm 37$ vs. $77 \pm 44 \mathrm{~min}, \mathrm{P}=0.475)$, and use of left ITA $(97.7 \%$ vs. $96.9 \%, \mathrm{P}=0.685)$ were equivalent for the two groups (Table 2). Bilateral ITAs and SVGs were more frequently used in the OPB-CABG group.

\section{Unadjusted outcomes}

The early death rates were $2.4 \%(n=6)$ in the OPB-CABG group and $0.5 \%(\mathrm{n}=2)$ in the $\mathrm{C}-\mathrm{CABG}$ group $(\mathrm{P}=0.087)$. Concerning early major morbidities, the patients in the OPB-CABG group were significantly more susceptible to acute kidney injury requiring dialysis $(\mathrm{P}<0.001)$ than those in the $\mathrm{C}-\mathrm{CABG}$ group. The incidence of other morbidities was not significantly different between the two groups (Table 2).

During a median follow-up of 81.0 months [quartiles 1-3, 66.6-95.0 months; 4,129.9 patient-years (PYs)], there were 52 all-cause deaths $(3.7 \% / \mathrm{PY})$ in the OPB-CABG group and 66 
Table 1 Baseline characteristics of patients in the OPB-CABG and C-CABG groups

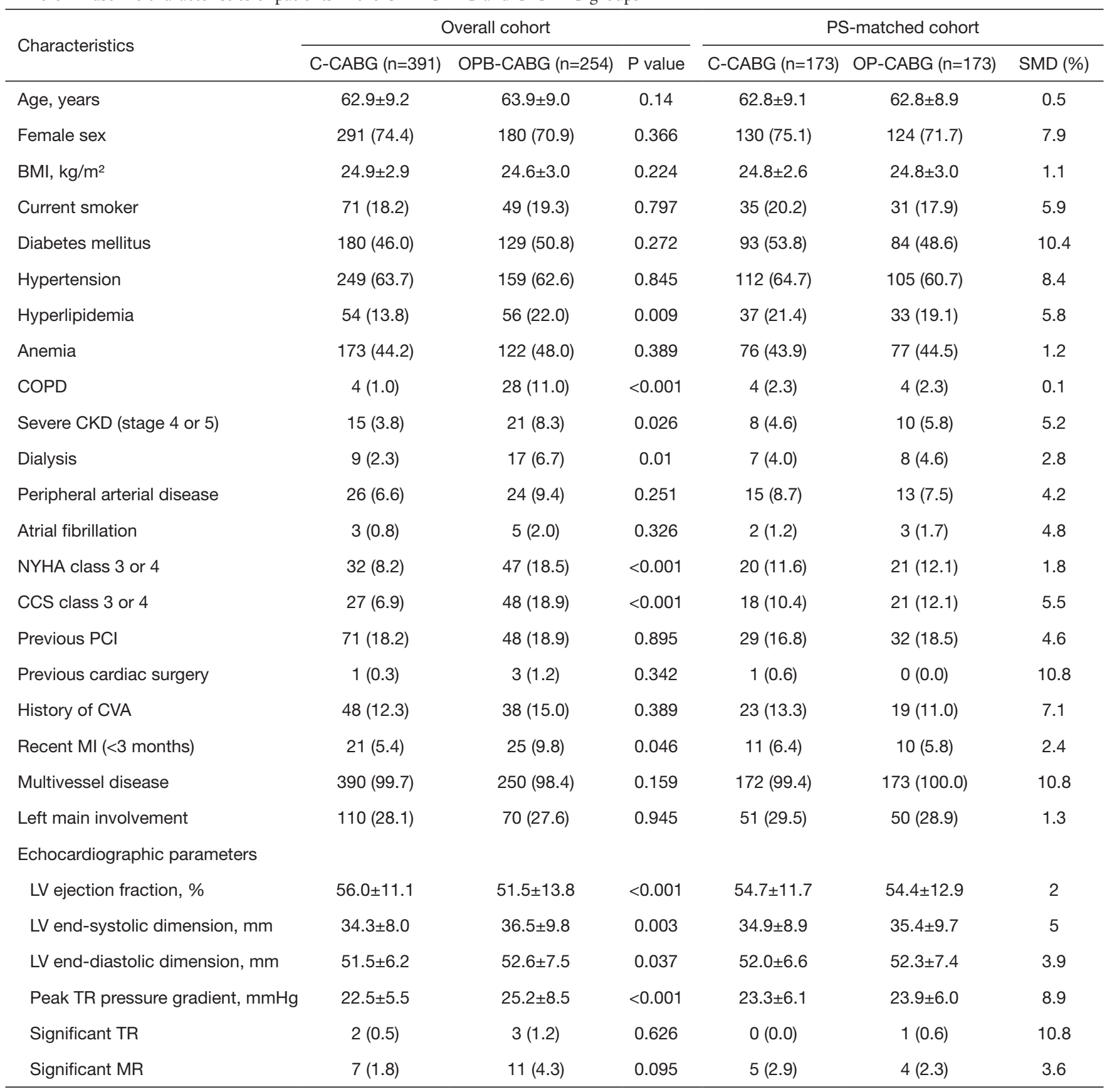

Values are $\mathrm{n}(\%)$ or mean \pm standard deviation, unless otherwise indicated. OPB-CABG, on-pump beating heart coronary artery bypass grafting; C-CABG, conventional coronary artery bypass grafting; PS, propensity score; BMI, body mass index; COPD, chronic obstructive pulmonary disease; CKD, chronic kidney disease; LV, left ventricular; NYHA, New York Heart Association; CCS, Canadian Cardiovascular Society; PCI, percutaneous coronary intervention; CVA, cerebrovascular accident; MI, myocardial infraction; MR, mitral regurgitation; TR, tricuspid regurgitation; SMD, standardized mean difference. 
Table 2 Operative profiles and outcomes

\begin{tabular}{|c|c|c|c|}
\hline Variables & C-CABG $(n=391)$ & OPB-CABG $(n=254)$ & $P$ value \\
\hline \multicolumn{4}{|l|}{ Operative profiles } \\
\hline No. of distal anastomosis & $3.0 \pm 0.9$ & $3.0 \pm 1.0$ & 0.816 \\
\hline \multicolumn{4}{|l|}{ Use of graft conduit } \\
\hline Left ITA & $382(97.7)$ & 246 (96.9) & 0.685 \\
\hline Radial artery & $328(83.9)$ & $80(31.5)$ & $<0.001$ \\
\hline Bilateral ITA & $0(0.0)$ & $17(6.7)$ & $<0.001$ \\
\hline Cardiopulmonary bypass time, min & $79 \pm 37$ & $77 \pm 44$ & 0.475 \\
\hline Aorta cross-clamping time, min & $55 \pm 26$ & - & - \\
\hline \multicolumn{4}{|l|}{ Early major morbidity } \\
\hline LCOS requiring MCS & $2(0.5)$ & $5(2.0)$ & 0.175 \\
\hline Early stroke & $4(1.0)$ & $4(1.6)$ & 0.799 \\
\hline Requirement for new dialysis & $3(0.8)$ & $15(5.9)$ & $<0.001$ \\
\hline Bleeding & $19(4.9)$ & $15(5.9)$ & 0.689 \\
\hline Pneumonia & $4(1.0)$ & $8(3.1)$ & 0.098 \\
\hline Sternal wound infection & $3(0.8)$ & $7(2.8)$ & 0.095 \\
\hline \multicolumn{4}{|l|}{ Long-term outcomes, n (\%/PY) } \\
\hline Revascularization & $5(0.2)$ & $5(0.4)$ & 0.314 \\
\hline Late stroke & $7(0.3)$ & $4(0.3)$ & 0.995 \\
\hline Hospitalization due to $\mathrm{CHF}$ & $8(0.3)$ & $14(1.0)$ & 0.003 \\
\hline Composite of death and MACE & $81(3.0)$ & $67(4.8)$ & 0.001 \\
\hline
\end{tabular}

Values are $\mathrm{n}(\%)$ or mean \pm standard deviation, unless otherwise indicated. ${ }^{*}, \chi^{2}$ test for early outcomes and log-rank test for late outcomes. OPB-CABG, on-pump beating heart coronary artery bypass grafting; C-CABG, conventional coronary artery bypass grafting; ITA, internal thoracic artery; SVG, saphenous vein graft; LCOS, low cardiac output syndrome; MCS, mechanical circulatory support; PY, patient-year; MACE, major adverse cardiac events; CHF, congestive heart failure.

(2.4\%/PY) in the $\mathrm{C}-\mathrm{CABG}$ group $(\mathrm{P}=0.005)$. The incidence of MACE $(1.6 \% / \mathrm{PY}$ vs. $0.8 \% / \mathrm{PY}, \mathrm{P}=0.030)$ was also higher in the OPB-CABG group, which was mainly attributable to the more frequent hospitalization for heart failure of the patients in this group (1.0\%/PY vs. $0.3 \% / \mathrm{PY}, \mathrm{P}=0.003)$.

\section{Adjusted outcomes}

In multivariate Cox proportional hazard models, increased age, severe CKD, atrial fibrillation, and reduced left ventricular ejection fraction were found to be associated with an increased risk for all-cause death or the composite 
Table 3 Operative outcomes in the propensity score-matched cohort

\begin{tabular}{|c|c|c|c|}
\hline Clinical outcomes & C-CABG $(n=173)$ & OPB-CABG $(n=173)$ & $P$ value \\
\hline Early ( $<30$ days) death & $0(0.0)$ & $2(1.2)$ & 0.478 \\
\hline \multicolumn{4}{|l|}{ Early major morbidity } \\
\hline LCOS requiring MCS & $0(0.0)$ & $1(0.6)$ & $>0.99$ \\
\hline Requirement for new dialysis & $2(1.2)$ & $8(4.6)$ & 0.109 \\
\hline Bleeding & $9(5.2)$ & $5(2.9)$ & 0.413 \\
\hline Pneumonia & $0(0.0)$ & $2(1.2)$ & 0.478 \\
\hline Sternal wound infection & $1(0.6)$ & $4(2.3)$ & 0.368 \\
\hline All-cause death & $34(2.8)$ & $30(3.0)$ & 0.506 \\
\hline MACE & $11(0.9)$ & $14(1.4)$ & 0.325 \\
\hline Myocardial infarction & $2(0.2)$ & $1(0.1)$ & 0.585 \\
\hline Revascularization & $3(0.2)$ & $4(0.4)$ & 0.551 \\
\hline Late CVA & $3(0.2)$ & $2(0.2)$ & 0.792 \\
\hline Hospitalization due to $\mathrm{CHF}$ & $5(0.4)$ & $9(0.9)$ & 0.148 \\
\hline Composite of death and MACE & $42(3.5)$ & $40(4.0)$ & 0.382 \\
\hline
\end{tabular}

Values are $\mathrm{n}(\%)$ or mean \pm standard deviation, unless otherwise indicated. $\chi^{2}$ test for early outcomes and log-rank test for late outcomes. OPB-CABG, on-pump beating heart coronary artery bypass grafting; C-CABG, conventional coronary artery bypass grafting; LCOS, low cardiac output syndrome; MCS, mechanical circulatory support; CVA, cerebrovascular accident; PY, patient-year; MACE, major adverse cardiac events; $\mathrm{CHF}$, congestive heart failure.

of death and MACE. The CPB strategy (OPB vs. conventional), however, did not significantly influence the risk of all-cause death $(\mathrm{P}=0.333)$ or the composite of adverse outcomes ( $\mathrm{P}=0.098$; Table S1).

The baseline profiles were well balanced between the two groups with SMDs $<10 \%$ for most covariates after PS matching (Table 1). In the PS-matched pairs, the incidence of early mortality and early major morbidities were comparable between the two groups (Table 3).

The results of risk analyses for the early and long-term clinical outcomes of the OPB strategy are summarized in Table 4. Patients in the OPB-CABG group showed an increased risk of acute kidney injury requiring new dialysis $(\mathrm{P}=0.001)$, all-cause death $(\mathrm{P}=0.006)$, and MACE $(\mathrm{P}=0.033)$ in the overall cohort. After PS matching, however, the OPB strategy did not significantly influence the risk of early complications including the need for new dialysis $(\mathrm{P}=0.074)$ and early stroke $(\mathrm{P}>0.99)$.

With regards to the long-term outcomes, the risks of allcause death [hazard ratio (HR), 1.19; 95\% confidence interval (CI), 0.72-1.95; P=0.507], MACE (HR, 1.49; 95\% CI, 0.673.31; $\mathrm{P}=0.328$ ), and the composite of death and MACE (HR, $1.21 ; 95 \% \mathrm{CI}, 0.78-1.89 ; \mathrm{P}=0.381$ ) were similar for the two groups in the PS-matched pairs (Table 4, Figure 1).

Likewise, when PS matching from the log-binomial method was performed (Table S2), the incidence of early and long-term outcomes between the two groups was comparable (Table S3). The risk of early and long-term outcomes was not significantly affected by the OPB strategy (Table S4).

\section{Discussion}

This article describes our institutional experiences with OPB-CABG and its clinical outcomes compared with 
Table 4 Comparative outcomes of OPB-CABG versus conventional CABG

\begin{tabular}{|c|c|c|c|c|c|c|}
\hline Outcomes & \multicolumn{3}{|c|}{ Overall cohort } & \multicolumn{3}{|c|}{ PS-matched cohort } \\
\hline \multicolumn{7}{|l|}{ Early outcomes } \\
\hline Early death & 4.71 & $1.07-32.29$ & 0.059 & NA & NA & NA \\
\hline LCOS requiring MCS & 3.91 & $0.83-27.42$ & 0.105 & NA & NA & NA \\
\hline New dialysis & 8.12 & $2.64-35.31$ & 0.001 & 4.15 & $1.02-27.74$ & 0.074 \\
\hline Bleeding & 1.23 & $0.60-2.46$ & 0.562 & 0.54 & $0.16-1.60$ & 0.282 \\
\hline Pneumonia & 3.15 & $0.98-11.89$ & 0.064 & NA & NA & NA \\
\hline Sternal wound infection & 3.67 & $1.01-17.13$ & 0.062 & 4.07 & $0.59-80.08$ & 0.211 \\
\hline All-cause death & 1.69 & $1.16-2.45$ & 0.006 & 1.19 & $0.72-1.95$ & 0.507 \\
\hline MACE & 1.93 & $1.05-3.53$ & 0.033 & 1.49 & $0.67-3.31$ & 0.328 \\
\hline Death + MACE & 1.73 & $1.25-2.41$ & 0.001 & 1.21 & $0.78-1.89$ & 0.381 \\
\hline
\end{tabular}

Early outcomes are given as odds ratio; long-term outcomes are given as hazard ratio. Cox proportional hazard assumption (by scaled Schoenfeld residuals): death $(P=0.917)$, MACE $(P=0.790)$, composite outcome $(P=0.974)$. OPB-CABG, on-pump beating heart coronary artery bypass grafting; C-CABG, conventional coronary artery bypass grafting; PS, propensity score; OR, odds ratio; HR, hazard ratio; CI, confidence interval; LCOS, low cardiac output syndrome; MCS, mechanical circulatory support; MACE, major adverse cardiac events; NA, not applicable.
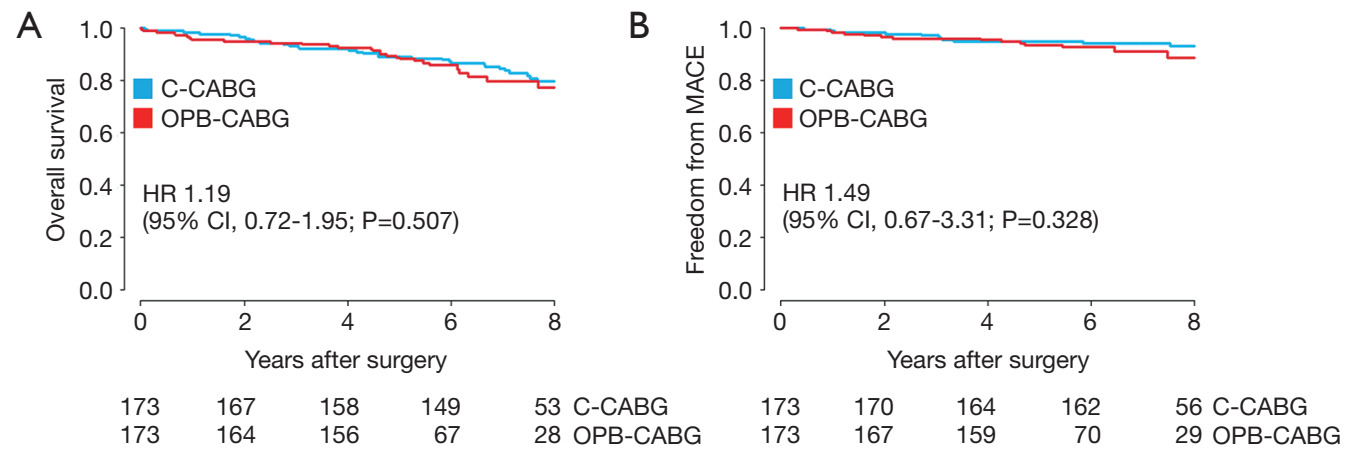

Figure 1 Kaplan-Meier curves for (A) overall survival and (B) freedom from MACE in the propensity score-matched cohorts. MACE, major adverse cardiac event; OPB-CABG, on-pump beating heart coronary artery bypass grafting; C-CABG, conventional coronary artery bypass grafting.

those of C-CABG. As suggested by previous studies demonstrating the clinical advantages of the OPB strategy in high-risk patients (7-11), patients who underwent OPBCABG had more morbidities than those who underwent $\mathrm{C}-\mathrm{CABG}$ in this study. The OPB strategy provided comparable early and long-term clinical outcomes to those of C-CABG in a selected set of patients with similar morbidities. To our knowledge, the present cohort represents one of the largest volume in which the two strategies were compared. A PS method was used to adequately balance the risk profiles between the two groups.

Since its introduction in the 1990 s, OPCAB has 
gradually gained acceptance as a potentially ideal method which may allow the major complication risks of C-CABG, including but not limited to embolic stroke, renal dysfunction, and the physiologic derangements of systemic inflammatory response to be avoided $(3,4,15)$. By obviating aortic cross-clamping and the use of $\mathrm{CPB}, \mathrm{OPCAB}$ was believed to be particularly advantageous for treating highrisk patients with low cardiac reserves $(4,15-17)$. Despite the promising early outcomes reported with OPCAB, extensive meta-analyses, randomized controlled trials, and rigorously adjusted retrospective studies have increasingly reported less favorable long-term survival outcomes after OPCAB compared with C-CABG $(1,2,5,6)$. Furthermore, situations requiring urgent unexpected conversion to onpump surgery have been reported to significantly increase the risk of mortality and postoperative complications (18-20). In this respect, the OPB-CABG strategy has presented as a reasonable method of providing stable hemodynamic support and coronary blood flow while avoiding aortic manipulations and cardioplegic arrest (7). Despite its postulated physiological advantages, the OPB strategy has generated less interest than the other two strategies due to the uncertainty regarding any differential benefits with this technique. Consequently, relatively few separate in-depth analyses were conducted and no large volume studies have been performed. Thus, the present study analyzing and comparing the 2 strategies may provide useful insights regarding this less commonly adopted method of coronary bypass surgery.

In the present study, crude intergroup comparison showed a higher incidence of early and long-term adverse clinical events in the OPB-CABG group patients (Table 2). This may be attributable in part to the greater proportion of patients with prominent high-risk profiles in the OPBCABG group such as severe CKD or recent myocardial infarction (Table 1). Due to intergroup disparities in some of the important risk factors, the two groups were analyzed and compared after PS matching. The results showed no significant differences in the early and long-term clinical outcomes; the two groups showed similar early outcomes such as mortality $(\mathrm{P}=0.478)$, low cardiac output syndrome $(\mathrm{P}>0.99)$, stroke $(\mathrm{P}>0.99)$, and new postoperative dialysis requirements $(\mathrm{P}=0.109$; Table 3). Furthermore, risk analyses in the PS-matched pairs showed no significant intergroup differences in all-cause death $(\mathrm{P}=0.507)$, MACE $(\mathrm{P}=0.328)$, and the composite of adverse outcomes $(\mathrm{P}=0.381)$ (Table 4). Of note, the number of distal anastomosis was also comparable between the two groups $(3.0 \pm 0.9$ vs. $3.0 \pm 1.0$,
$\mathrm{P}=0.816$; Table 2), indicating that OPB-CABG was not a limitation to achieving a similar degree of completeness of revascularization to C-CABG. These finding showed that the OPB strategy may be comparable in safety level and efficacy compared to C-CABG in performing surgical coronary revascularization.

Dependence on CPB support is a limitation that may argue for the OPB strategy as being qualitatively similar to C-CABG. However, the obviation of aortic crossclamping and the need for cardioplegic arrest may provide cardio-protection against the obligate global intraoperative myocardial ischemia in C-CABG $(7,8)$. This may be particularly advantageous in acute myocardial infarction or poor left ventricular function with low cardiac reserve as these patients may be unable to tolerate the extreme myocardial manipulation of OPCAB or the controlled ischemia of C-CABG $(9,10,21,22)$. Compared with OPCAB, CPB-assisted beating heart surgery may afford a stable surgical platform for ensuring optimal anastomosis quality that would otherwise not be possible with $\mathrm{OPCAB}$ as the heart is continuously perfused while being protected from distention injury and the anastomosis site is securely stabilized (23-25).

Despite these postulated benefits of the OPB strategy, additional significant advantages of obviating aortic crossclamping and cardioplegic arrest with the OPB-CABG group were not clearly apparent in either the early or long-term comparisons with C-CABG. This may be attributable to the limited sample size which may not have been sufficiently powered to show an actual inter-group difference with respect to the primary hard endpoints, particularly in the subgroup of patients with highrisk profiles. In this regard, our study results should be interpreted accordingly, and warranting further randomized controlled trials over a larger volume of patients to confirm and objectively validate the benefits of the OPB strategy and to identify the patient subgroup most likely to benefit from this therapeutic approach.

\section{Limitations}

This study has limitations inherent to retrospective and observational single-center studies. Because our study included coronary procedures performed by five different well-seasoned surgeons having different CPB and revascularization strategies, the possibility of surgical bias remains at issue. In addition, despite the similarity in surgeon skill levels, unmeasured confounders outside the 
range of adjustments made with PS matching may have influenced the study outcomes. We could not systematically evaluate and compare the completeness of revascularization and long-term graft patency between the two groups due to the limited availability of data for these assessments. Although the present study was focused on the clinical outcomes relating to the $\mathrm{CPB}$ strategy, the question of how the specific factors relating to each may influence the longterm clinical outcomes remain at issue that needs to be clarified through further randomized trials.

\section{Conclusions}

The OPB strategy was preferred over the conventional strategy during surgical revascularization in patients with significant morbidities in a real-world practice setting. The OPB strategy showed safety and efficacy comparable to the conventional strategy during CABG in selected patients that were matched for similar risk profiles. Although obviating aortic cross-clamping and cardioplegic arrest did not show a significantly greater clinical benefit compared to the conventional strategy as expected, a prospective randomized trial over a larger volume of patients may be warranted to better validate the beneficial impact of OPB-CABG as both a viable and a durable alternative strategy to $\mathrm{C}-\mathrm{CABG}$.

\section{Acknowledgements}

None.

\section{Footnote}

Conflicts of Interest: The authors have no conflicts of interest to declare.

Ethical Statement: The study was approved by the institutional ethics committee/review board of Asan Medical Center (No. 2016-0225), which waived the requirement for informed consent owing to the retrospective study design.

\section{References}

1. Shroyer AL, Grover F, Hattler B, et al. On-pump versus Off-pump Coronary-Artery Bypass Surgery. N Engl J Med 2009;361:1827-37.

2. Khan NE, Souza AD, Mister R, et al. A Randomized Comparison of Off-pump and On-pump Multivessel Coronary-Artery Bypass Surgery. N Engl J Med
2004;350:21-8.

3. Mills SA. Cerebral injury and cardiac operations. Ann Thorac Surg 1993;56:S86-91.

4. Bucerius J, Gummert JF, Walther T, et al. Impact of offpump coronary bypass grafting on the prevalence of adverse perioperative outcome in women undergoing coronary artery bypass grafting surgery. Ann Thorac Surg 2005;79:807-12; discussion 812-3.

5. Takagi H, Umemoto T. Worse long-term survival after off-pump than on-pump coronary artery bypass grafting. $\mathrm{J}$ Thorac Cardiovasc Surg 2014;148:1820-9.

6. Kim JB, Yun SC, Lim JW, et al. Long-term survival following coronary artery bypass grafting: off-pump versus on-pump strategies. J Am Coll Cardiol 2014;63:2280-8.

7. Chaudhry UA, Harling L, Sepehripour AH, et al. BeatingHeart Versus Conventional On-Pump Coronary Artery Bypass Grafting: A Meta-Analysis of Clinical Outcomes. Ann Thorac Surg 2015;100:2251-60.

8. Ueki C, Sakaguchi G, Akimoto T, et al. On-pump beatingheart technique is associated with lower morbidity and mortality following coronary artery bypass grafting: a meta-analysis. Eur J Cardiothorac Surg 2016;50:813-21.

9. Miyahara K, Matsuura A, Takemura H, et al. On-pump beating-heart coronary artery bypass grafting after acute myocardial infarction has lower mortality and morbidity. J Thorac Cardiovasc Surg 2008;135:521-6.

10. Izumi $Y$, Magishi K, Ishikawa N, et al. On-pump beatingheart coronary artery bypass grafting for acute myocardial infarction. Ann Thorac Surg 2006;81:573-6.

11. Mizutani S, Matsuura A, Miyahara K, et al. On-pump beating-heart coronary artery bypass: a propensity matched analysis. Ann Thorac Surg 2007;83:1368-73.

12. Kim HJ, Lee TY, Kim JB, et al. The impact of sequential versus single anastomoses on flow characteristics and midterm patency of saphenous vein grafts in coronary bypass grafting. J Thorac Cardiovasc Surg 2011;141:750-4.

13. Lauer MS, Blackstone EH, Young JB, et al. Cause of Death in Clinical Research. J Am Coll Cardiol 1999;34:618-20.

14. Kurth T, Walker AM, Glynn RJ, et al. Results of multivariable logistic regression, propensity matching, propensity adjustment, and propensity-based weighting under conditions of nonuniform effect. Am J Epidemiol 2006;163:262-70.

15. Murkin JM, Boyd WD, Ganapathy S, et al. Beating Heart Surgery: Why Expect Less Central Nervous System Morbidity? Ann Thorac Surg 1999;68:1498-501.

16. Al-Ruzzeh S, Nakamura K, Athanasiou T, et al. Does off-pump coronary artery bypass surgery improve the 
outcome in high-risk patients. Eur J Cardiothorac Surg 2003;23:50-5.

17. Marui A, Okabayashi H, Komiya T, et al. Benefits of offpump coronary artery bypass grafting in high-risk patients. Circulation 2012;126:S151-7.

18. Borowski A, Korb H. Myocardial infarction in coronary bypass surgery using on-pump, beating heart technique with pressure- and volume-controlled coronary perfusion. J Card Surg 2002;17:272-8.

19. Légaré JF, Buth KJ, Hirsch GM. Conversion to on pump from OPCAB is associated with increased mortality: results from a randomized controlled trial. Eur J Cardiothorac Surg 2005;27:296-301.

20. Perrault LP, Menasché P, Peynet J, et al. On-Pump, Beating-Heart Coronary Artery Operations in HighRisk Patients: An Acceptable Trade-off? Ann Thorac Surg 1997;64:1368-73.

21. Rastan AJ, Eckenstein JI, Hentschel B, et al. Emergency coronary artery bypass graft surgery for acute coronary

Cite this article as: Kim $\mathrm{HJ}$, Oh YN, Ju MH, Kim JB, Jung SH, Chung CH, Lee JW, Choo SJ. On-pump beating heart versus conventional coronary artery bypass grafting: comparative study on early and long-term clinical outcomes. J Thorac Dis 2018;10(5):2656-2665. doi: 10.21037/jtd.2018.05.14 syndrome: beating heart versus conventional cardioplegic cardiac arrest strategies. Circulation 2006;114:I477-85.

22. Brown WR, Moody DM, Challa VR, et al. Longer duration of cardiopulmonary bypass is associated with greater numbers of cerebral microemboli. Stroke 2000;31:707-13.

23. Gould BL, Clayton PD, Jensen RL, et al. Association between early graft patency and late outcome for patients undergoing coronary artery bypass surgery Circulation 1984;69:569-76.

24. Fitzgibbon GM, Kafka HP, Leach AJ, et al. Coronary bypass graft fate and patient outcome: angiographic followup of 5,065 grafts related to survival and reoperation in 1,388 patients during 25 years. J Am Coll Cardiol 1996;28:616-26.

25. Synnergren MJ, Ekroth R, Oden A, et al. Incomplete revascularization reduces survival benefit of coronary artery bypass grafting: role of off-pump surgery. J Thorac Cardiovasc Surg 2008;136:29-36. 


\section{Supplementary}

Table S1 Multivariate predictors of all-cause death and the composite of death and MACE (Cox regression)

\begin{tabular}{|c|c|c|c|c|c|c|}
\hline Risk factors & \multicolumn{3}{|c|}{ All-cause death } & \multicolumn{3}{|c|}{ Composite of death and MACE } \\
\hline Age (by 1-year increment) & 1.07 & $1.05-1.09$ & $<0.001$ & 1.05 & $1.03-1.07$ & $<0.001$ \\
\hline Severe CKD (stage 4 or 5 ) & 5.03 & $3.03-8.35$ & $<0.001$ & 4.09 & $2.57-6.51$ & $<0.001$ \\
\hline Atrial fibrillation & 6.99 & $2.82-17.35$ & $<0.001$ & 8.62 & $3.75-19.77$ & $<0.001$ \\
\hline LVEDD (by 1-mm increment) & 0.94 & $0.89-0.995$ & 0.033 & - & - & - \\
\hline OPB vs. conventional strategy & 1.23 & $0.81-1.87$ & 0.333 & 1.34 & $0.95-1.89$ & 0.098 \\
\hline
\end{tabular}

Only variables with $\mathrm{P} \leq 0.10$ in univariate analysis were included in the multivariate analysis. MACE, major adverse cardiac events; OR, odds ratio; $\mathrm{Cl}$, confidence interval; CKD, chronic kidney disease; LVEF, left ventricular ejection fraction; LVEDD, left ventricular enddiastolic dimension; OPB, on-pump beating. 
Table S2 Baseline characteristics in the PS-matched cohort (log-binomial method)

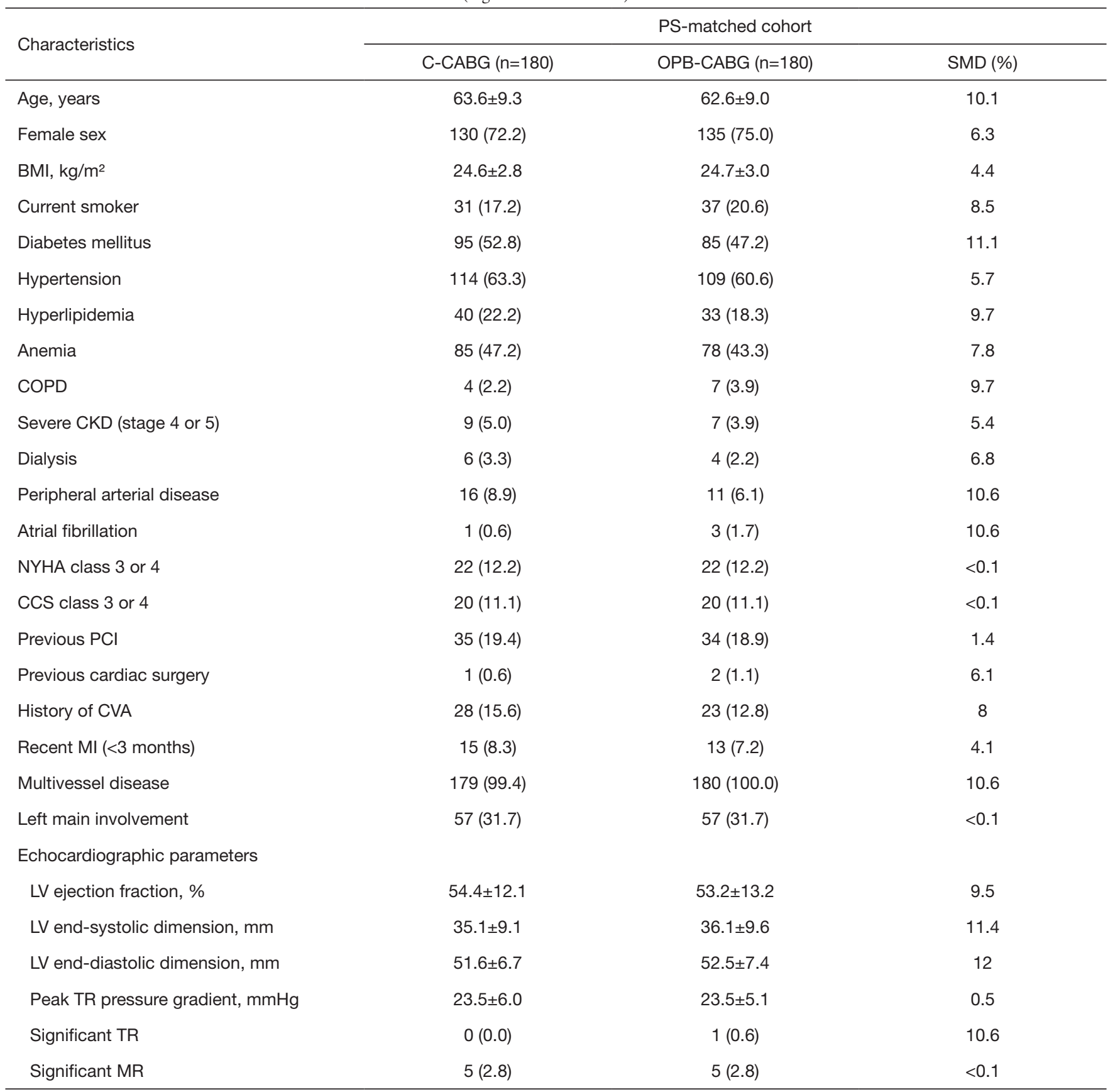

Values are $\mathrm{n}(\%)$ or mean \pm standard deviation, unless otherwise indicated. OPB-CABG, on-pump beating heart coronary artery bypass grafting; C-CABG, conventional coronary artery bypass grafting; PS, propensity score; BMI, body mass index; COPD, chronic obstructive pulmonary disease; CKD, chronic kidney disease; LV, left ventricular; NYHA, New York Heart Association; CCS, Canadian Cardiovascular Society; PCI, percutaneous coronary intervention; CVA, cerebrovascular accident; MI, myocardial infraction; MR, mitral regurgitation; TR, tricuspid regurgitation; SMD, standardized mean difference. 
Table S3 Operative outcomes in the PS-matched cohort (log-binomial method)

\begin{tabular}{|c|c|c|c|}
\hline Clinical outcomes & C-CABG $(n=180)$ & OPB-CABG $(n=180)$ & $P$ value \\
\hline \multicolumn{4}{|l|}{ Early outcomes, n (\%) } \\
\hline Early (<30 days) death & $0(0.0)$ & $3(1.7)$ & 0.246 \\
\hline \multicolumn{4}{|l|}{ Early major morbidity } \\
\hline LCOS requiring MCS & $0(0.0)$ & $2(1.1)$ & 0.478 \\
\hline Requirement for new dialysis & $2(1.1)$ & $9(5.0)$ & 0.066 \\
\hline Bleeding & $9(5.0)$ & $7(3.9)$ & 0.798 \\
\hline Pneumonia & $2(1.1)$ & $4(2.2)$ & 0.681 \\
\hline Sternal wound infection & $1(0.6)$ & $5(2.8)$ & 0.217 \\
\hline All-cause death & $34(2.5)$ & $30(2.4)$ & 0.46 \\
\hline MACE & $13(0.9)$ & $12(0.9)$ & 0.779 \\
\hline Myocardial infarction & $1(0.1)$ & $1(0.1)$ & 0.946 \\
\hline Revascularization & $2(0.1)$ & $4(0.3)$ & 0.288 \\
\hline Late CVA & $5(0.4)$ & $1(0.1)$ & 0.142 \\
\hline Hospitalization for $\mathrm{CHF}$ & $6(0.4)$ & $8(0.6)$ & 0.301 \\
\hline Composite of death and MACE & $44(3.3)$ & $39(3.3)$ & 0.487 \\
\hline
\end{tabular}

Values are $\mathrm{n}(\%)$ or mean \pm standard deviation, unless otherwise indicated. $\chi^{2}$ test for early outcomes and log-rank test for late outcomes. OPB-CABG, on-pump beating heart coronary artery bypass grafting; C-CABG, conventional coronary artery bypass grafting; LCOS, low cardiac output syndrome; MCS, mechanical circulatory support; CVA, cerebrovascular accident; PY, patient-year; MACE, major adverse cardiac events; $\mathrm{CHF}$, congestive heart failure. 
Table S4 Comparative outcomes of OPB-CABG versus conventional CABG in the PS-matched cohort (log-binomial method)

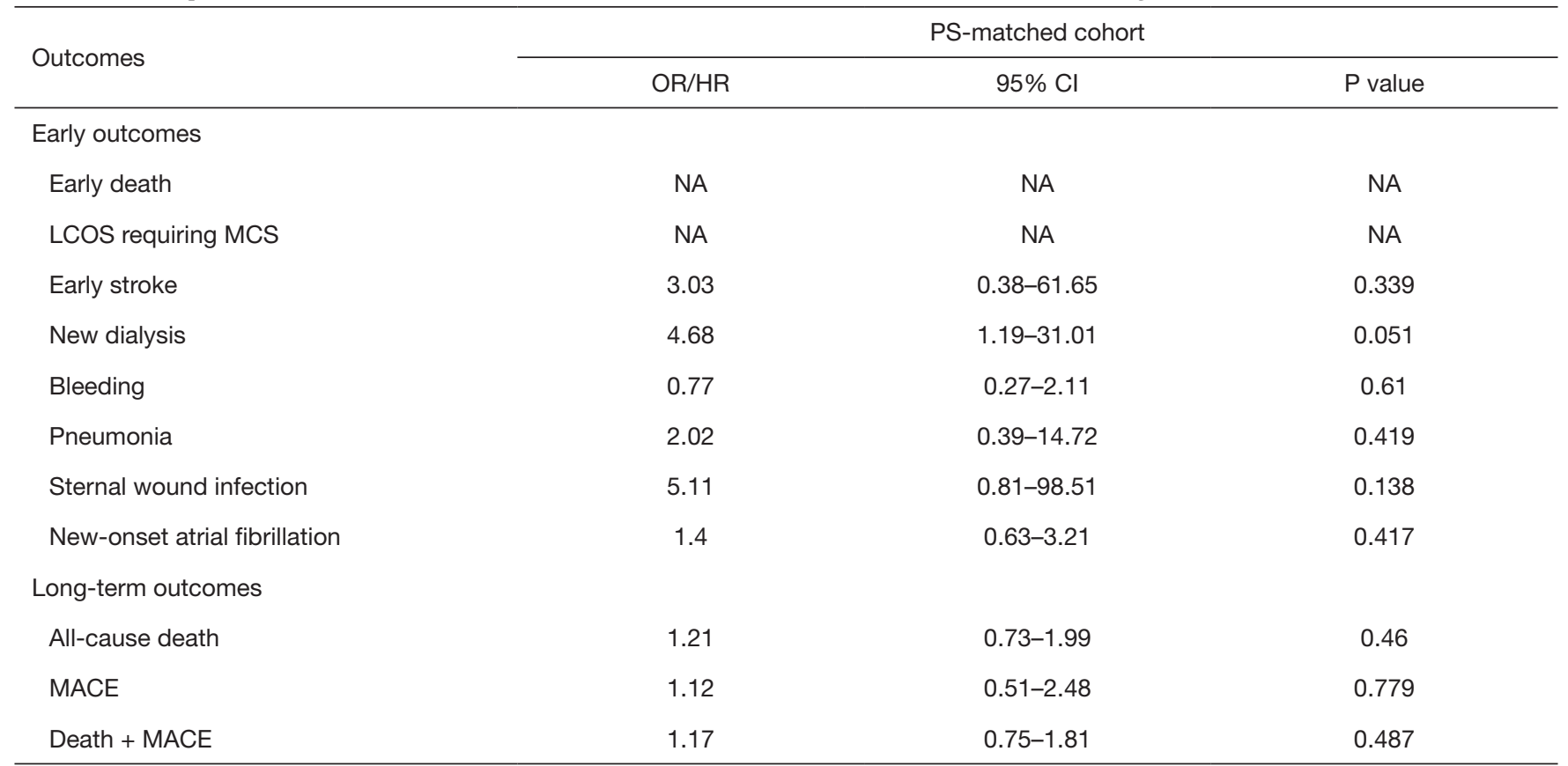

Early outcomes are given as odds ratios; long-term outcomes are given as hazard ratios. Cox proportional hazard assumption (by scaled Schoenfeld residuals): death $(P=0.873)$, MACE $(P=0.997)$, composite outcome $(P=0.885)$. $P S$, propensity score; OR, odds ratio; HR, hazard ratio; $\mathrm{Cl}$, confidence interval; LCOS, low cardiac output syndrome; MCS, mechanical circulatory support; MACE, major cardiac adverse event; NA, not applicable. 